
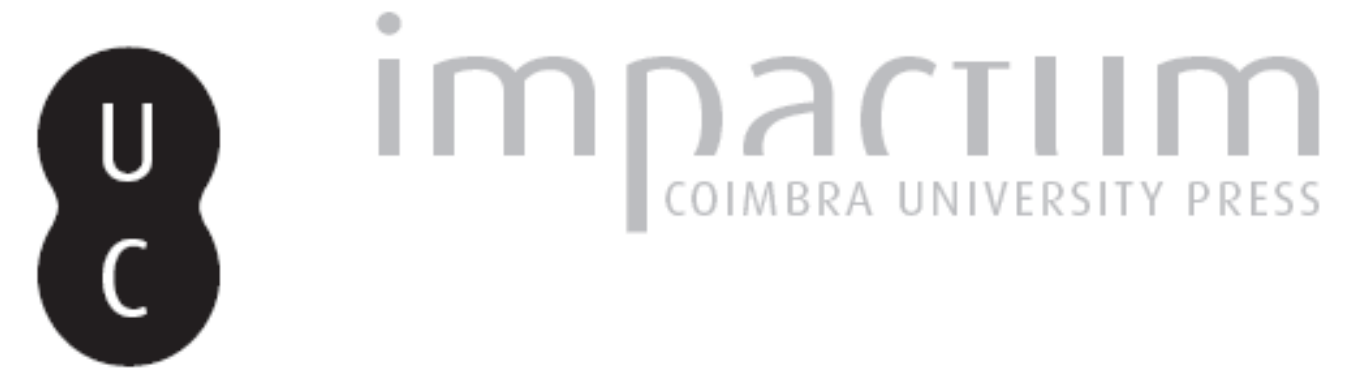

\title{
A epígrafe latina como elemento didático (XXXIII): o colégio dos sêxviros: religião e poder em evidência
}

Autor(es): $\quad$ Encarnação, José d'

Publicado por: Imprensa da Universidade de Coimbra

URL persistente:

URI:http://hdl.handle.net/10316.2/37524

DOI:

DOI:http://dx.doi.org/10.14195/0872-2110_59_7

Accessed : $\quad$ 26-Apr-2023 14:18:54

A navegação consulta e descarregamento dos títulos inseridos nas Bibliotecas Digitais UC Digitalis, UC Pombalina e UC Impactum, pressupõem a aceitação plena e sem reservas dos Termos e Condições de Uso destas Bibliotecas Digitais, disponíveis em https://digitalis.uc.pt/pt-pt/termos.

Conforme exposto nos referidos Termos e Condições de Uso, o descarregamento de títulos de acesso restrito requer uma licença válida de autorização devendo o utilizador aceder ao(s) documento(s) a partir de um endereço de IP da instituição detentora da supramencionada licença.

Ao utilizador é apenas permitido o descarregamento para uso pessoal, pelo que o emprego do(s) título(s) descarregado(s) para outro fim, designadamente comercial, carece de autorização do respetivo autor ou editor da obra.

Na medida em que todas as obras da UC Digitalis se encontram protegidas pelo Código do Direito de Autor e Direitos Conexos e demais legislação aplicável, toda a cópia, parcial ou total, deste documento, nos casos em que é legalmente admitida, deverá conter ou fazer-se acompanhar por este aviso.

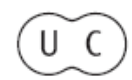


COIMBRA • 2014

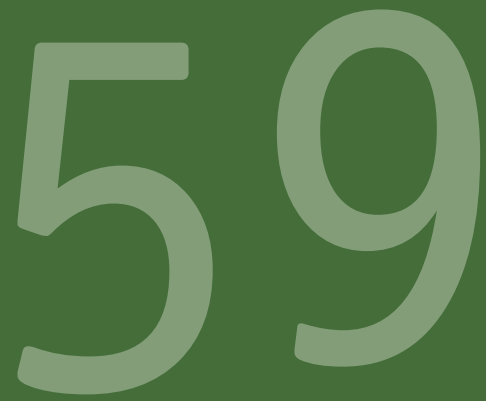

\title{
BOLETIM DE
}

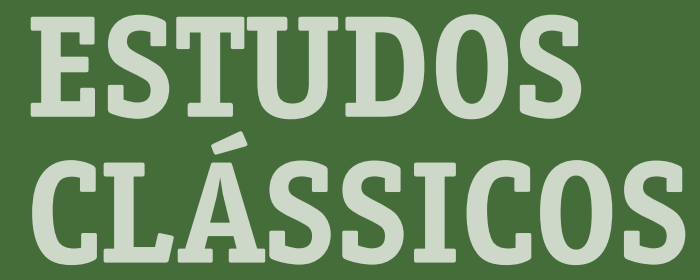

\author{
ASSOCIAÇÃO \\ PORTUGUESA \\ DE ESTUDOS \\ CLÁSSICOS \\ INSTITUTO \\ DE ESTUDOS \\ CLÁSSICOS
}




\section{A EPÍGRAFE LATINA COMO ELEMENTO DIDÁCTICO (XXXIII): O COLÉGIO DOS SÊXVIROS - RELIGIÃO E PODER EM EVIDÊNCIA}

\section{(THE LATIN EPIGRAPHY AS A DIDACTIC ELEMENT (XXXIII): THE COLLEGE OF SEVIRI - RELIGION AND POWER IN EVIDENCE)}

JOSÉ D'ENCARNAÇÃO

UC - CENTRO DE ESTUDOS DE ARQUEOLOGIA, ARTES E CIÊNCIAS DO PATRIMÓNIO

Resumo: Procura mostrar-se, através da análise da actividade dos sêxviros, como a religião e o poder se encontram intimamente ligados durante a época romana. Assinala-se que eram predominantemente os libertos que integravam este colégio sacerdotal relacionado com o culto ao imperador.

Exemplifica-se com uma epígrafe de Balsa (IRCP 73), em que um sêxviro agradece à deusa Fortuna Augusta o ter sido eleito, atestando que cumpriu assim as promessas eleitorais.

Palavras-chave: seviri; augustales; religião e poder político.

Abstract: By examining the seviri's activities present in the Roman epigraphic monuments, we seek to show how religion and the political power were closely connected during that time.

Freedmen are the members of this college related to the worship of the emperor an epigraphic evidence (IRCP 73) of Balsa, a civitas in the south 
of Lusitania, shows us how a sevir thanks the goddess Fortuna Augusta for his election, with the promised organisation of pleasing events.

Keywords: seviri; augustales; religion and political power.

\section{O COLÉGIO DOS SÊXVIROS - RELIGIÃO E PODER EM EVIDÊNCIA}

Celebra-se, neste ano de 2014, o bimilenário da morte do imperador Augusto. Foi oficialmente considerado divus, e Tibério, o seu sucessor, promoveu-lhe o culto, porque dessa sorte também ficaria beneficiado, ele que detestava a ostentação e, assim, era a divina memória de Augusto que poderia continuar a envolver o seu reinado.

Estranhar-se-á, porventura e à primeira vista, essa palavra 'divinização', ainda que aplicada a alguém já falecido. Trata-se, porém, afinal, de um procedimento mais comum do que parece:

- os restos mortais de Amália Rodrigues e, agora, de Sophia de Mello Breyner Andresen deram entrada no Panteão Nacional, lugar simbólico de uma 'divinização' também, porque «panteão» é lugar para todos os deuses;

- e, a 27 de Abril, p. p., o Papa Francisco canonizou João XXIII e João Paulo II, entronizando-os, assim, no rol dos santos, considerando-os, pois, participantes de uma centelha divina, faróis a alumiar caminhos!...

Assim, em tempo de Romanos. O imperador, após a morte, corria três riscos, como todos nós: a maldição (e seu nome seria, inclusive, martelado nas inscrições, para que a sua memória se danasse - damnatio memoriae), a indiferença ou a divinização.

Não quis abertamente o primeiro imperador que lhe fosse outorgada qualquer prerrogativa divina, ainda que se não tivesse olvidado de escolher, como nome, algo que dos deuses era apanágio: a capacidade de 
aumentar o bem-estar dos seus concidadãos. Augustus se quis chamar, pois se auspiciava que de todo afastaria angústias. Também recusou, como se sabe, o título de pontífice máximo enquanto foi vivo quem o detinha - e disso, aliás, faz gala nas Res Gestae (10.2).

Paulatinamente, porém, o seu culto mesmo em vida se foi organizando por todo o Império, inclusive a nível local e provincial, servido pelos flâmines e pelo colégio dos sêxviros. Destes importa agora discorrer.

\section{OS SÊXVIROS AUGUSTAIS}

Uma bem conhecida inscrição de Balsa (Tavira) dá conta das festividades levadas a efeito por Annius Primitivus, como forma de se regozijar por ter sido eleito sêxviro - ob honorem IIIIIvir(atus) sui - e, de certo modo, para assim cumprir de imediato as promessas feitas aquando da campanha eleitoral: edito barcarum certamine et pugilum sportulis etiam civibus datis. ${ }^{1}$ Era obrigatório o dispêndio de determinada importância em prol da comunidade - summa honoraria - e Annius Primitivus assim se apressou a fazer e lapidarmente o consignou: de sua pecunia dono dedit. A epígrafe é, todavia, assumida como ex-voto de reconhecimento à deusa Fortuna Augusta.

Trata-se, naturalmente, de uma epígrafe que se presta a inúmeros comentários, inclusive no domínio da língua, mormente se quiséssemos optar aqui por seguir à risca o objectivo geral destas notas: «a epígrafe latina como elemento didáctico». Permita-se-me que se deixem estas pistas por explorar agora, uma vez que a tónica do culto imperial se integra na temática própria da celebração do bimilenário da morte de quem, após ela, divus se tornou.

Também não virá ao caso a discussão - quiçá mais académica do que real - acerca da distinção entre augustales, seviri e seviri augustales,

1 IRCP 73. Ver foto infra, p. 103. 
que os investigadores têm amiúde dissecado com propriedade e saber. ${ }^{2}$ Alinhavem-se, porém, algumas ideias a esse respeito, só para se ficar desde logo com uma noção do que estava realmente em causa.

Assim, no que concerne à diversidade de designações, que Robert Duthoy procurara sistematizar, ${ }^{3}$ é bem provável, primeiro, que só teoricamente hajam correspondido a funções específicas; e, depois, que os dedicantes das epígrafes se tivessem preocupado - ou tivessem conhecimentos bastantes - em usar a terminologia adequada. Não deixa, por isso, de ser sintomática, por exemplo, a opção de Marco Buonocore, que, ao propor o exemplo da Regio IV para trazer luz acerca da difusão dos augustais, explica que usa o termo *Augustales para designar, «para além das associações dos Augustales, dos seviri Augustales e dos magistri Augustales, também as dos seviri nude dicti, porquanto nem sempre é fácil determinar o significado da designação seviri Augustales e demais categorias afins, se nos quisermos ater à categorização proposta por Duthoy». ${ }^{4}$

Independentemente das distinções que Robert Duthoy intentou propor, é importante o seu estudo acerca da «função social» que essa categoria sacerdotal implicava, inclusive para melhor se compreender o relevo que há a dar à inscrição de Balsa.

Pelas contas que pôde fazer, Duthoy verificou que eram libertos $85 \%$ dos seviri augustales, $92 \%$ dos augustales e apenas 66\% dos seviri (art. cit., p. 134, n. 1), concluindo que os augustales eram «essencialmente associações de libertos» (p. 141).

Interrogando-se sobre o motivo que levaria uma pessoa a candidatar-se a essas funções (p. 151-154), esclarece que seria uma espécie de con-

2 Indiquem-se, a título de exemplo, as contribuições de Robert Duthoy, seguramente o investigador que mais atenção dedicou a este tema. Cite-se dele: 1974: 134-154 e, de modo especial, a grande síntese: 1978: 1254-1309.

3 1970: 88-105.

4 Buonocore: 1995 123-139. Também José Miguel Serrano Delgado esboçou idêntica proposta quantitativa em relação ao Ocidente: 1993, 147-155. Aliás, esse estudo vem na sequência da sua obra de 1988, cujo apêndice $n^{\circ}$ I (p. 152-169) se ocupa expressamente da «terminologia de la Augustalidad». 
sagração do seu êxito social, atendendo a que, como apenas libertos, não gozavam de regalias reservadas aos cidadãos livres. Sêxviros, passavam a ter direito a lugares reservados nos espectáculos e em sessões públicas, como os magistrados; podiam envergar a toga praetexta; acompanhavam-nos lictores com fasces; saíam, enfim, do anonimato e um factor psicossociológico deve ter exercido igualmente um papel deveras relevante: podiam imitar os gestos dos ingenui ricos, inclusive, e sobretudo, no que concerne aos sempre prestigiantes donativos...

Contudo, segundo Duthoy, a pompa, os sacrifícios às divindades, a organização de jogos (ludi), a oferta de um banquete (epulum) constituíam, de certo modo, uma obrigação contraída, um compromisso assumido, pelo que não se pode, sem mais, integrar, por exemplo, um banquete no rol dos actos benemerentes.

\section{PARA MELHOR SE ENTENDER IRCP 73}

Creio bem que não haverá grande margem para erro se afirmarmos não ser do quotidiano provincial essa preocupação rígida de atribuir, nas epígrafes, a designação correcta da função. G. Humbert, no artigo de síntese que assinou no Dictionnaire des Antiquités Grecques et Romaines, de Daremberg et Saglio, s. v. «Augustales» (p. 560-561), não hesita em afirmar que, embora oficialmente o colégio dos sêxviros haja sido criado por Tibério, naquele seu desejo de honrar soberanamente a gens Iulia, já antes as centenas de inscrições gravadas por todo o Império proclamavam um culto ao imperador reinante. Não posso deixar de concordar com esta opinião, acrescentando que o panorama que se nos oferece na Lusitânia ocidental é o de que são os libertos quem se candidata maioritariamente a integrar esse colégio. Compreende-se porquê: primeiro, pelas regalias que a função lhes dá, como atrás se viu; depois, porque, na verdade, nas suas mãos estará a maior parte a economia da civitas, porquanto, libertos sem dúvida de uma família 
endinheirada e de elevado estatuto sociopolítico, disso importava fazer ostentação para maiores favores ainda se granjear.

Assim, teremos de considerar em Balsa uma gens Annia notável, em que não haverá, porventura, muita dificuldade em incluir o L. Annius Lapillianus, quiçá liberto também, integrado na extensa lista de beneméritos identificada em Faro, a vizinha Ossonoba (IRCP 10), e os dois $L$. Annii de que há notícia em zona mineira de Cortes Pereira, Alcoutim, falecidos ambos com a provecta idade de 85 anos (IRCP 91). E é bem provável que outros testemunhos mais venham a ser encontrados.

Por ter sido eleito sêxviro (ob honorem seviratus sui), promoveu Primitivo uma batalha naval, um combate de gladiadores e distribuiu sportulae pelos cidadãos. Mas... não pertence ele a um colégio? Os outros cinco companheiros de funções terão, também eles, organizado festejos? Creio não se haver encontrado em nenhuma cidade do Império documentação que, posta em paralelo, permita concluir que essa era a atitude normal e que cada um tomava as suas iniciativas. O mais natural era que sim, pois certamente não seriam todos libertos da mesma família; e, por outro lado, tinham os romanos uma elevada noção de 'democracia', de equilíbrio social, de partilhado usufruto de benesses (pelo menos na aparência) no seio das classes privilegiadas... E então? Ficamos na dúvida. E, perante essa eventualidade, esfregam os epigrafistas as mãos de contentes, uma vez que é suposto bastantes mais epígrafes virem a ser encontradas. Pusera-me, de facto, a mesma questão em relação ao pedestal dedicado divo Augusto por (apenas) dois augustais de Olisipo: 5 não pertenceriam, também estes, a um colégio e não era previsível que todos haveriam de contribuir para a erecção de um monumento pomposo e de não menosprezável dispêndio? Permitiram as outras famílias que seus créditos se não afirmassem também?...

Releve-se, por fim, a circunstância de o pretexto para se perpetuar numa epígrafe o gesto de Primitivus ter sido, como se frisou, o da con-

5 Quinteira e Encarnação: 2009: 181-187. 
sagração a Fortuna Augusta. Não se trata de um vulgar "pôr-se em bicos de pés', para que imorredoiramente conste. Não: o que está em causa é um legítimo acto devoto, a consagração feita a uma significativa divindade! Significativa, porque é a Fortuna, a deusa que preside à promoção económica e social; significativa, porque também de Augusta é chamada, pois o sêxviro deve zelar pelo culto do imperador e a fortuna alcançada terá resultado, sem dúvida, da intercessão de uma e... dos favores do outro! o poder político e o poder económico em comunhão, nimbados de um sublime halo religioso...

\section{BIBLIOGRAFIA CITADA}

Buonocuore, M., "Per uno studio sulla diffusione degli *Augustales nel mondo romano: l'esempio della Regio IV Augustea”, Zeitschrift für Papyro-logie und Epigraphik, 108, 1995: 123-139.

Duthoi, R., (1970), “Notes onomastiques sur les Augustales. Cognomina et indication de statut”, L'Antiquité Classique, 39, 1970, 88-105.

Duthoi, R. (1974), “La fonction sociale de l'augustalité”, Epigraphica, 36, 1974: 134-154.

Duthoi R. (1978), “Les Augustales” ANRW II 16. 2, 1978: 1254-1309.

Encarnação, J. d' ('2013), Inscrições Romanas do Conventus Pacensis (= IRCP), Coimbra, ${ }^{1}$ 1984, (2ª edição disponível em: http://hdl.handle.net/10316/578).

Quinteira, C., Encarnação, J. d' (2009), “CIL II 182, de Olisipo”, Conimbri-ga, 48: 181-187. Acessível em: http://hdl.handle.net/10316/13088.

Serrano Delgado, J. M. (1988), Status y Promoción Social de los Libertos en Hispania Romana, Sevilha.

Serrano Delgado, J. M., (1993), "El numero de augustales en las ciudades dell'Occidente romano: una propuesta cuantitativa", $2^{\circ}$ Congresso $\mathrm{Pe}$ ninsular de História Antiga. Actas, (Coimbra, 18-20 de Outubro de 1990), Coimbra: 147-155. 

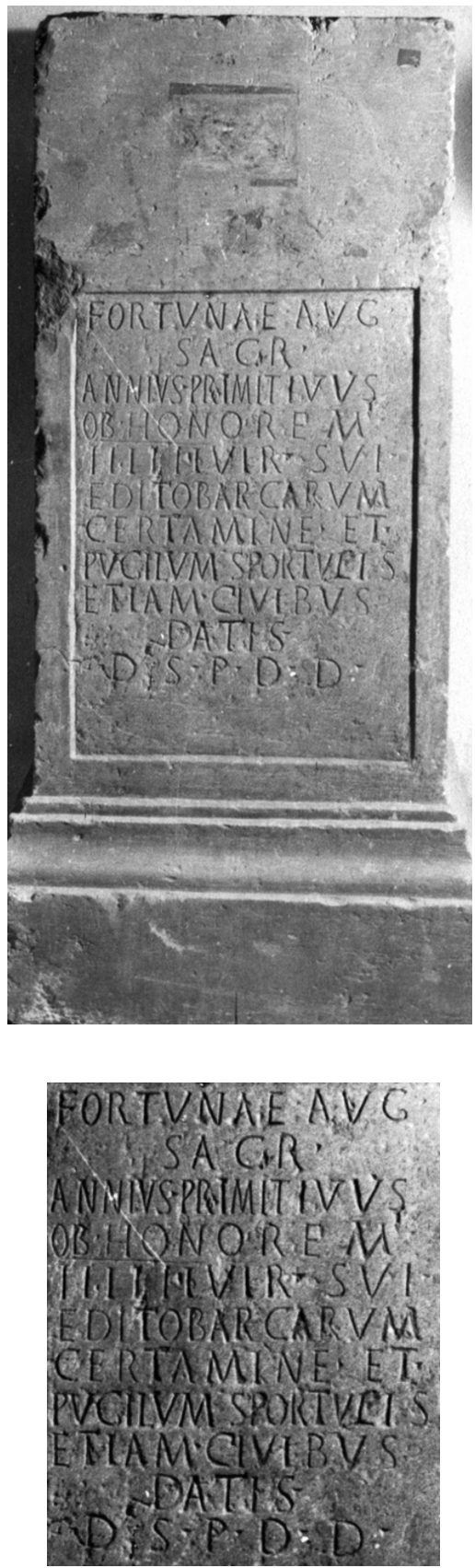